\title{
Early Warning Indicator Model of Financial Developments Using an Ordered Logit
}

\author{
Hans-Eggert Reimers \\ Hochschule Wismar \\ Postfach 1210, 23952 Wismar, Germany \\ E-mail: Hans-Eggert.Reimers@wi.hs-wismar.de
}

Received: November 2, 2012 Accepted: November 17, 2012

doi:10.5296/ber.v2i2.2897ＵRL: http://dx.doi.org/10.5296/ber.v2i2.2897

\begin{abstract}
The recent financial crisis has demonstrated in an impressive way that boom/bust cycles can have devastating effects on the real economy. This paper aims at contributing to the literature on early warning indicator exercises for asset price development. Using a sample of 17 industrialised OECD countries and the euro area over the period 1969 Q1 - 2011 Q2, an asset price composite indicator incorporating developments in both stock and house price markets is constructed. The latter is then further developed in order to identify periods that can be characterised as asset price booms and busts. The subsequent empirical analysis is based on an ordered logit-type approach incorporating several monetary, financial and real variables. Following some statistical tests, credit aggregates, the interest rate spread together with the house price growth gap and stock price developments appear to be useful indicators for the prediction of asset price developments.
\end{abstract}

JEL-classification: E37, E44, E51, G01

Keywords: House prices, Stock prices, Asset price boom-bust-cycle, Ordered logit model

\section{Introduction}

The recent financial crisis starting 2007 has shown that boom-bust-cycles can have devastating effects on the real economy. At least since the Great Depression, economists and policy-makers have become aware of the potentially damaging effects of large fluctuations in asset prices, such as equity and property prices. The recent experiences in the 1980s-1990s in 
Japan, in 2000s in Iceland as well as Ireland and other countries have confirmed that, in some circumstances, boom-bust-cycles in asset prices can be very damaging as they may lead to financial and ultimately to macroeconomic instability.

Against this background, it is important to have indicators to assess the possible implications of large asset price movements and the building up of financial imbalances in the economy. In this respect, several recent studies have shown that the analysis of monetary and credit developments may be very useful (see for example Borio et al. 1994, Adalid, Detken 2007, Gerdesmeier, Reimers, Roffia 2010, 2011). There are, in fact, several reasons why monetary and asset price developments tend to be positively correlated. One reason is that both sets of variables may react in the same direction to monetary policy or cyclical shocks to the economy. For example, strong money and credit growth may be indicative of a too lax monetary policy which leads to the creation of excessive liquidity in the economy and fuels excessive price changes in the asset markets. Moreover, there can be self-reinforcing mechanisms at work. For example, during asset price booms the balance sheet positions of the financial and non-financial sectors improve and the value of collateral increases, permitting a further extension of the banking credit for investment which may reinforce the increase in asset prices. The opposite mechanism can sometimes be observed during asset price downward adjustments.

Most of the studies have in common that the development of the financial indicator is mapped into a bivariate variable. It gets a unity for boom or bust periods and a zero elsewhere (see Yucel 2011). This paper contributes to the literature on the early warning system that it maps the financial indicator development into three phases: booms, normal period and busts. It extends the works of Gerdesmeier, Reimers and Roffia (2010) analyzing busts and Gerdesmeier, Reimers and Roffia (2011) investigating booms. To forecast the movement of the variable an ordered logit-type approach is applied. This approach uses the higher information content of the variable than a multinomial logit model suggested by Bussiere and Fratzscher (2006) which explain the pre- and post-crisis as well as the normal periods. Explanatory variables are, for example, lending boom, interest rate spread and house price growth. Moreover, it characterizes the comprehensive development of the indicator from boom over normal to busts periods. The description of the whole boom-bust-cycle is more general than the approach of Singh (2010) who uses an ordered probit approach, however, defines two phases of downturn.

The paper is structured as follows. Section 2 briefly summarizes the available evidence on the indicator properties of money and credit for detecting asset price imbalances, with a focus on the most recent contributions. Section 3 briefly describes the data used for the empirical analysis and describes the criterion to define an asset price phases. It also presents some results based on an ordered logit-type approach, using the pooled estimation procedure. In Section 4 we present some robustness checks of the model, and Section 5 draws some conclusions. 


\section{Literature on Money, Credit and Asset Price Developments}

Gerdesmeier, Reimers and Roffia (2011) mention that evidence that money and credit could be important for the analysis of asset price developments is not new. Already at the beginning of the 20th century, Fisher (1932) had analysed the reasons for various booms and depressions, emphasising, among other things, the role of the debt structure and, in particular, the debt contracted to leverage the acquisition of speculative assets for subsequent resale as possible sources of financial instabilities. Moreover, he stressed the role of monetary factors by pointing to the fact that, basically, in all cases, real interest rates had been too low and thus monetary factors had been "fuelling the flames". Forty years later, Kindleberger (1978) provided a comprehensive history of financial crises. He started with the South Sea bubble (1717-1720), to illustrate common threads. His work is illustrative of the idea that historically booms and bursts in asset markets had been strongly associated with large movements in monetary and, especially, credit aggregates.

The view that credit developments may contain useful indications in times of sharp asset price fluctuations was further explored by Borio, Kennedy and Prowse (1994). On the basis of an aggregate asset price index for several industrialised countries (based on the combination of residential property, commercial property and share prices), the authors examined the factors (inter alia credit and money) behind the observed movements in the index over the 1970s and 1980s. They concluded that ratio of private credit to nominal GDP contains useful incremental information to predict movements in the real asset price index, in addition to more standard determinants such as real profits, nominal GDP growth and the long-term nominal interest rates, possibly reflecting the impact of the relaxation of credit constraints on the aggregate price index developments during the 1980s.

Moreover, Vogel (2010) presents a summary of the results of some studies regarding bubbles of the last three centuries. First, it seems that the availability of money and credit beyond what is needed to finance real GDP growth tends to stimulate speculative activity, which might end into an asset price bubble. Second, crashes seem to occur when there is an insufficient amount of cash or additional credit available to service the debt incurred. Third, crashes are characterized by relatively rapid price changes whereas a bubble, from a behavioural perspective, seems to be characterised by a longer build-up period. A bubble coincides with a period of euphoria while a crash is linked to fears. Hence, Vogel (2010) stresses the difference between booms and busts. Prechter (1999) states that hope tends to build slowly while fear often crystalizes swiftly. This argumentation is also put forward by Greenspan (2009). In particular, the latter states that bubbles seem to be connected with periods of prosperity, moderate inflation and moderate long-term interest rates which feed euphoria, thereby driving a bubble. By contrast, a contraction phase of credit and business cycles, driven by fear, have historically been far shorter and for more abrupt than expansion phases.

Regarding the definition of bubbles, Brunnermeier (2008) defines them as episodes when asset prices exceed an asset's fundamental value due to the fact that current owners believe that they can resell the asset at an even higher price in the future, whereas Grantham (2008) 
states that bubbles are definable events when the prices exceed a threshold marked by a two standard deviations away from a long-term trend.

More recently, a new strand of the literature (including work by several international organizations such as the BIS, the ECB and the IMF) has started investigating in a systematic manner episodes of asset price misalignments and/or financial crises with the aim to derive common stylized facts across the different episodes and, more specifically, to identify possible early indicators that could provide warning signals to policy makers. Yucel (2011) gives a survey of early warning models (see also Babecký et al. 2011). An overview is also given by Gerdesmeier, Reimers and Roffia (2011). Early warning model approaches are applied to analyse bubbles on stock markets as in Herwartz and Kholodilin (2011), whereas Angello and Schuknecht (2011) and Dreger and Kholodilin (2011) concentrate on house markets. Both markets are investigated by Borio and Lowe (2002) or Helbling and Terrones (2003) or as a composite asset constructed from these markets by Alessi and Detken (2009), Borio et al. or Gerdesmeier et al. (2010, 2011). Gerdesmeier et al. (2011) conclude that the identification and quantification of asset price imbalances represents an extremely difficult task, both ex ante and ex post. Many studies also confirm that - among other variables monetary and credit developments represent useful leading indicators of financial imbalances. In particular, one robust finding across the different studies is that measures of excessive credit creation are very good leading indicators of the building up of financial imbalances in the economy.

\section{Results From a Logit Model Analysis}

\subsection{General Set-up and Data Used}

The present study extends the analysis of Gerdesmeier, Reimers and Roffia $(2010,2011)$ which focused on predicting asset price busts and booms using different probit models, respectively. This analysis determines one model to predict the development of a financial indicator which includes booms and busts as well as normal periods. This necessitates, as a first step, precise definition of booms and busts. Given that this study's focus is on deriving a combined signal derived from several individual asset markets, a composite indicator combining stock and house price development is used. This is in line with the IMF (2010) which stresses the importance of the real estate market and the stock market to describe asset markets.

Once the respective boom and busts periods are selected, as a second step, we try to explain them by use of leading indicators represented by various financial, monetary and real indicators. This is also done by Gerdesmeier et al. (2010, 2011), Herwartz \& Kholodilin (2011) or Dreger \& Kholodilin (2011). As for the financial variables, we consider historical series of the short-term (three-month money market) and long-term (ten-year government bond yield) interest rates and their spreads. The short-term reflect the policy of the monetary authority. Relatively high rates show a restrictive policy and should reduce the probability of a boom and increase the probability of a bust. The long-term rate reflects the capital market. High rates indicate a high profitability of capital, which boost a boom in equity markets. The term spread, defined as difference between the long-term and the short-term rate may show the policy stance of the monetary policy. In the literature it has been shown that the term spread is a good 
measure to predict future output growth (see, for instance, Estrella and Hardouvelis 1991). Monetary indicators comprise broad money and credit to the private sector (or loans to the private sector whenever available). For example Borio et al. (1994) show that asset price booms are fuelled by money growth as well as credit growth. As for the real indicators, we consider real GDP growth and the investment-to-GDP ratio as well as the inflation rate measured by the growth rate of the consumer price index (CPI). High real GDP growth goes in line with high profits of firms and increase of stock prices. Moreover, economic agents obtain higher income and spend more money in the house markets. Furthermore, high output growth rates make companies optimistic and stimulate them to invest more. This positively affects the stock prices (see Gerdesmeier et al. 2011). In sum, the dataset contains quarterly data ${ }^{1}$ for 17 main industrial OECD countries (additionally, the euro area as a whole is included in the descriptive analysis) for the period 1969 Q1 - $2011 \mathrm{Q}^{2}{ }^{2}$

\subsection{Defining Bust Phases}

Our definition of busts follows the work of Gerdesmeier, Reimers and Roffia (2010). It relies on the methodologies developed by Berg and Pattillo (1999) and Andreou et al. (2007). A bust occurs when the "composite" asset market indicator declines by more than a pre-defined threshold. ${ }^{3}$ In line with this, a composite asset price indicator has been calculated by combining the stock price index with the house price index as follows: ${ }^{4}$

$$
\Delta C=\phi_{1} \Delta \text { Stock prices }+\phi_{2} \Delta \text { House prices }
$$

where $\phi_{1}$ is normalised to 1 and $\phi_{2}=\sigma_{\Delta S P} / \sigma_{\Delta H P}$ (that is the ratio of the standard deviation of the two variables). The weight is calculated recursively throughout the sample period in order to take into account the information available up to each moment in time.

A bust is then defined on the basis of this composite indicator, and, generally speaking, it would be denoted as a situation in which this indicator declines by a certain amount at the end of a certain period with respect to its peak (see Andreou et al., 2007). In our case, we will denote as occurrence of a bust (i.e. a value of 1 of the "bust dummy" variable) a situation in which at the end period the composite indicator has declined by more than its mean (denoted as $\bar{C}$ ) minus a

\footnotetext{
All series are seasonally adjusted; whenever possible, quarterly series are calculated as averages of monthly series. For a detailed description of the series used and their sources see Gerdesmeier, Reimers and Roffia (2009), Annex 3. For a few variables in some counties the starting point may be slightly later.

The intention of basing our analysis on a "composite" asset price index is that such an index would facilitate comparisons of broad asset price movements over time and across countries, give some empirical content notion of general asset prices "inflation" and "deflation" and highlight patterns of behaviours that would otherwise remained undetected.

$4 \quad$ This approach is a standard practice in the literature on currency crises, whereby the crisis indicators are usually obtained by statistical analysis of the exchange rate and official international reserve series. The weighting scheme used between the two series is generally inversely proportional to their conditional variance. When the pressure indicator goes above a certain threshold, it is deemed that there is a currency crisis. The threshold used is generally two or three standard deviations above the mean. The greater the number of the standard deviations, the smaller the number of identified crises.
} 
factor (in our study $\delta=1.5$ is chosen as fixed across the sample period) multiplied by the standard deviation of the same indicator $\left(\sigma_{C}\right)$ in the period from 1 to $(t+r)$ with respect to its maximum reached in the same period, i.e.:

$$
D_{u m b u_{t}}=1 \quad \text { iff } \quad \Delta C_{t} \leq\left(\left.\overline{\Delta C}\right|_{1} ^{t}-\left.\delta \sigma_{\Delta C}\right|_{1} ^{t}\right)
$$

where $C$ is the composite indicator (already expressed in terms annual rate of changes), $\overline{\Delta C}=\operatorname{mean}(\Delta C)$ and $\delta=1.5$. In the empirical application there are busts periods are underbroken by one or two no busts periods. In such cases we set these periods to busts periods to get a less volatile dummy behavior.

\subsection{Defining Boom Phases}

The definition of asset price booms overtakes the proposal of Gerdesmeier, Reimers and Roffia (2011). In the literature, several approaches to identify asset price booms have been used. For instance, Borio and Drehmann (2009) define a boom as a period in which the three-year moving average of the annual growth rate of asset prices is greater than the average growth rate (i.e. its mean) plus a multiple (1.3 in this specific case) of the standard deviation of the growth rates. By contrast, Alessi and Detken (2009) follow a different approach. In essence, they calculate the trend of the price variable using the one-sided Hodrick Proscott filter and then derive the gap between the actual values of the price variable and its trend measure. If the gap is greater than 1.75 times of the recursively determined standard deviation a boom will be identified. With respect to such a procedure, Detken, Gerdesmeier and Roffia (2010) note that these methods rest on some critical assumptions. First, there is an implicit acknowledgement that it is difficult to derive equilibrium asset prices with reference to the respective underlying fundamental variables. Second, the method relies on the use of a time-varying trend as a proxy for those underlying fundamentals. Third, significant deviations from the trend are then considered excessive and expected to be reversed at some point in future. Following these assumptions, a boom occurs when the "composite" asset market indicator development is greater than a pre-defined threshold. ${ }^{5}$ In this study, the trend is calculated by making use of the Christiano-Fitzgerald filter (2003), since the Hodrick-Prescott filter is well-known to suffer from an end-of-sample problem.

$G_{t}=C_{t}-C_{t}^{C F}$

The emergence of a boom (i.e. a value of 1 of the "boom dummy" variable) is defined as a

The intention of basing our analysis on a "composite" asset price index is that such an index would facilitate a comparison of broad asset price movements over time and across countries, give some empirical content to the notion of general asset price "inflation" and "deflation" and highlight patterns of behaviours that would otherwise remained undetected. Furthermore, Detken and Smets (2004) state that the bursting of bubbles will be more severe if more asset markets are involved, which would support the use of a composite indicator. For example, Zhang (2001) expresses his preference for individual market analyses. It should, however, be noted that combining two different markets (such as the housing and equity markets) in a single indicator can, in some cases, be misleading. This happens, for instance, when the two markets move sharply in opposite directions, so that the developments in the composite indicator would mask diverging trends and may not flag the risk existing in one of the two markets. 
situation in which the gap between the actual composite indicator and the indicator's trend has been greater than its mean $(\bar{G})$ plus a factor $\delta$ (equal to 1.75 and fixed across the sample period) multiplied by the standard deviation of the same indicator $\left(\sigma_{G}\right)$, which are calculated over a rolling period of 60 quarters:

$$
\text { Dumbo }_{t}=1 \quad \text { iff } \quad G_{t} \geq\left(\left.\bar{G}\right|_{s} ^{t}+\left.\delta \sigma_{G}\right|_{s} ^{t}\right)
$$

where $s=t-60$ for $t>60$ or 1 for $0<t<60 .{ }^{6}$ Putting both dummy definitions (2) and (4) together we determine the following ordered variable.

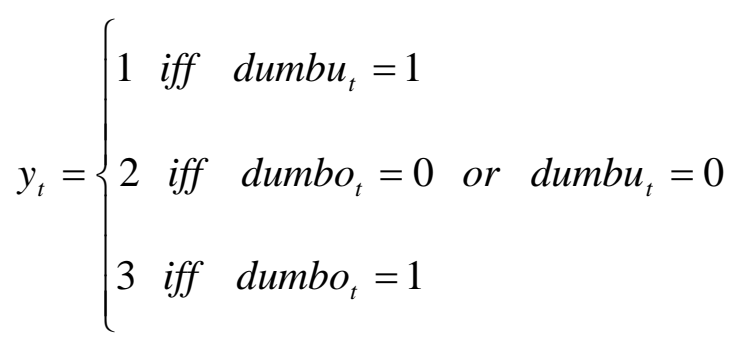

Figure 1 summarizes the behaviour of the changes of the composite indicator an of the $y_{t}$ of each country. As far as the euro area is concerned, only two booms can be detected, the first one from 1988 Q4 to 1991 Q4, which may be connected to the introduction of the common market and the second one from 2006 Q2 to 2007 Q4. It seems, however, that, at the aggregate level, developments in some countries are counterbalanced by movements in other regions of the euro area. Second; the overall number of booms seems to vary across countries. Third, the length of the booms also varies across countries, lasting from a few quarters up to, broadly speaking, two-three years. In addition, when looking at individual country's experience, a few interesting issues also arise when considering the most recent developments in relation to the driving factors. For instance, it is interesting to note that in countries like Spain, Ireland and the United States booms in the composite asset price market are detected around 2006-2007, which is a period when all three countries experienced a strong house price boom which had started some years earlier. ${ }^{7}$ However, it is important to take into account that developments in the composite asset price indicator are also influenced by developments in stock prices, which can in principle counterbalance house prices developments over some periods of time. Therefore, opposite developments in the two individual asset markets may lead to a lack of a signal of a boom. This is, for instance, the case for Germany where no boom can be detected in the most recent episode, given the subdued developments in house prices. ${ }^{8}$

\footnotetext{
6 The calculation of the indicator is based on running the procedure recursively and in a rolling manner from the beginning of the sample onwards. Of course, the choice of $\delta=1.75$ times the standard deviation is arbitrary.

7 In particular, in Ireland (Spain and United States) the house price race began in 1996 (1999 and 2000 , respectively).

$8 \quad$ It is also important to note that the boom definition applied in the analysis is based on the deviations of its trend. Therefore, in case of long-lasting but gradual deviations from the trend, it may take some time before a boom episode is actually detected. The boom phases presents turning points.
} 


\section{$\underline{\text { Australia }}$}

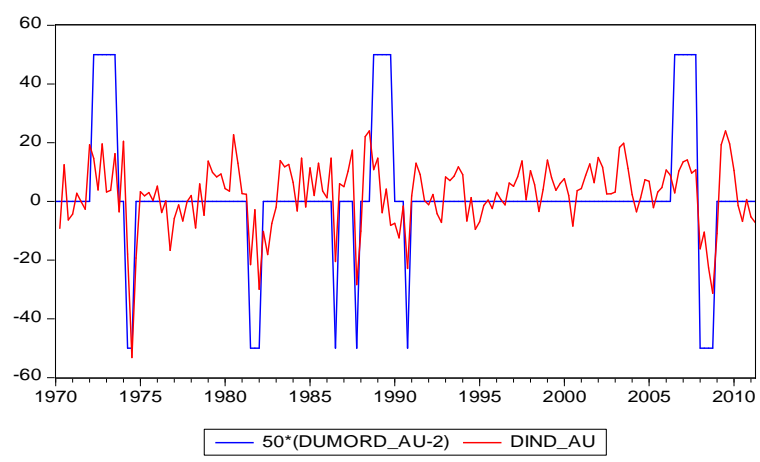

\section{Switzerland}

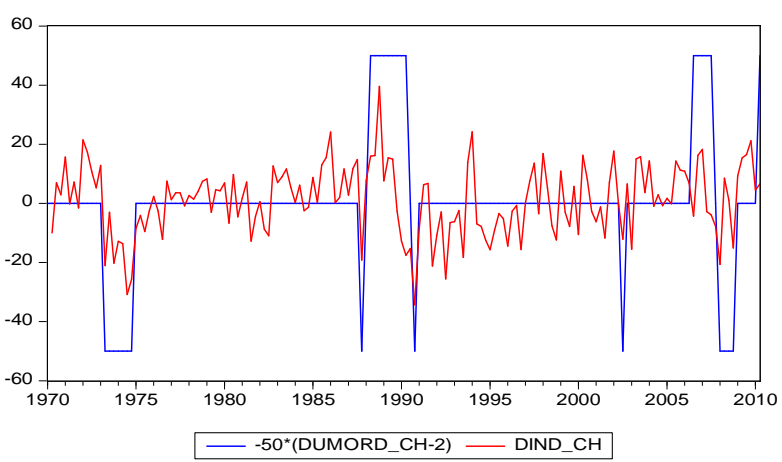

$\underline{\text { Denmark }}$

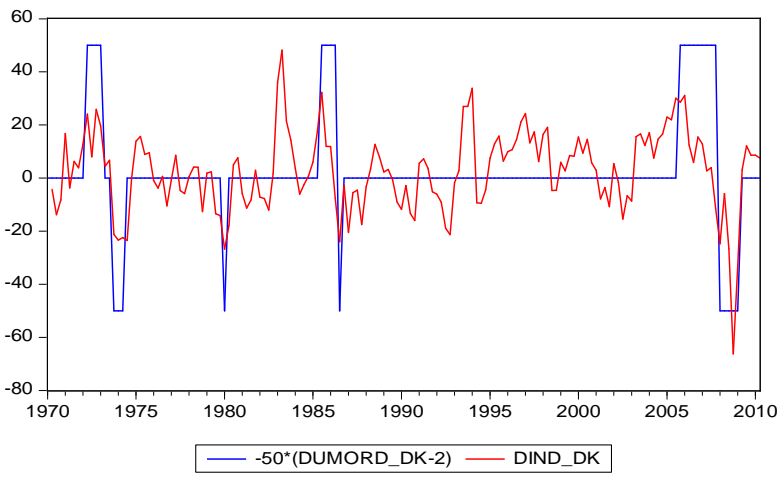

France

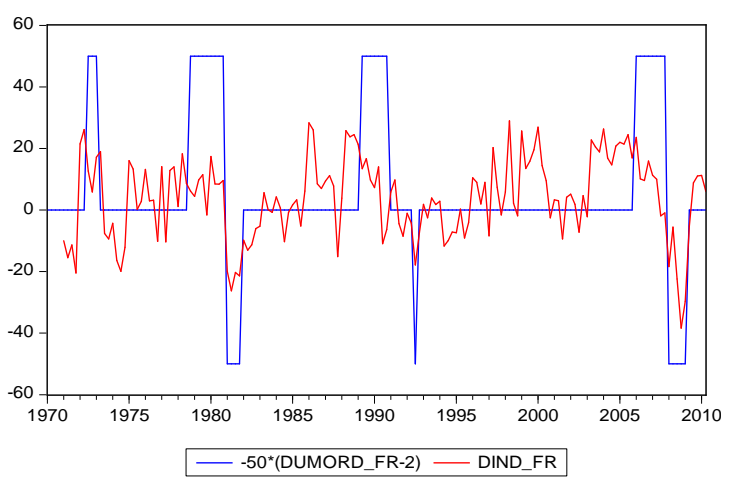

\section{Canada}

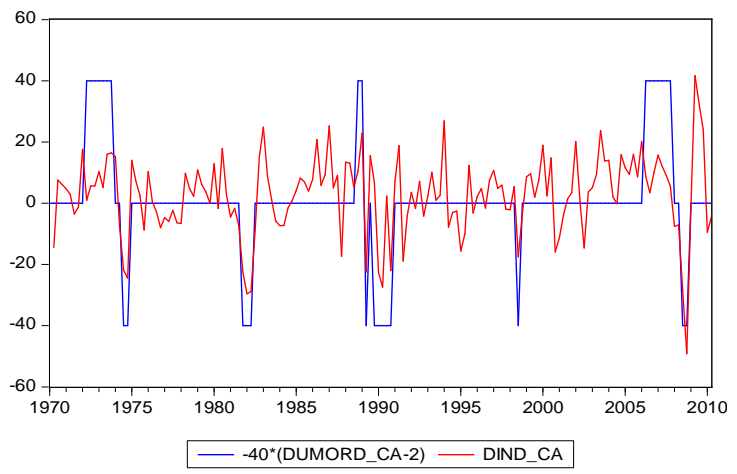

Germany

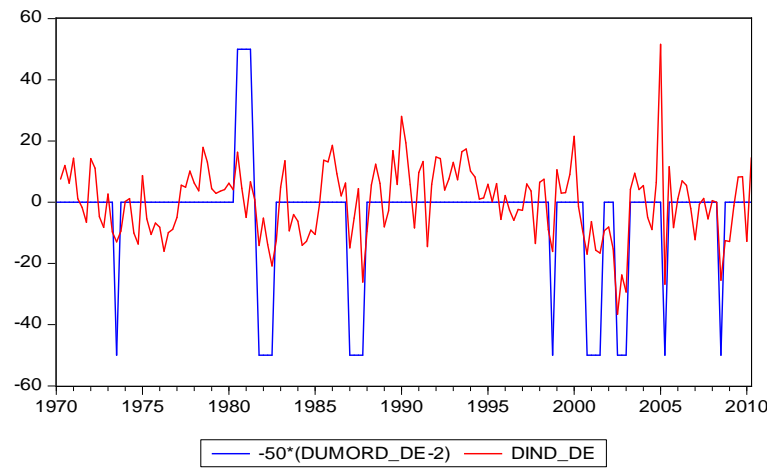

\section{$\underline{\text { Spain }}$}

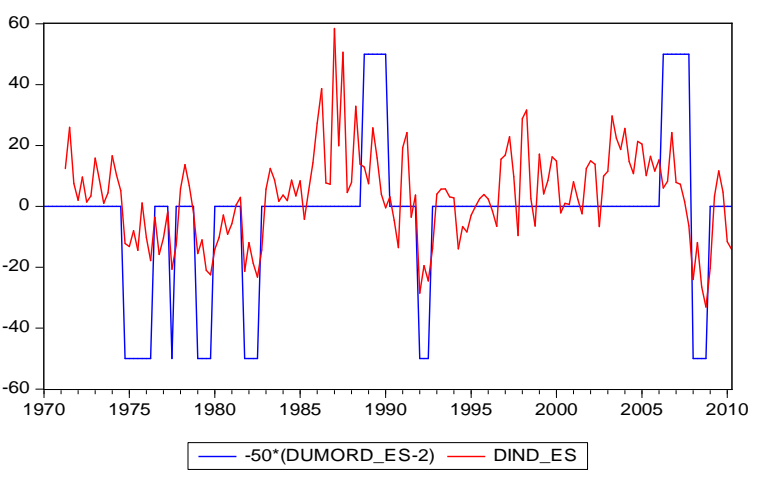

$\underline{\text { Ireland }}$

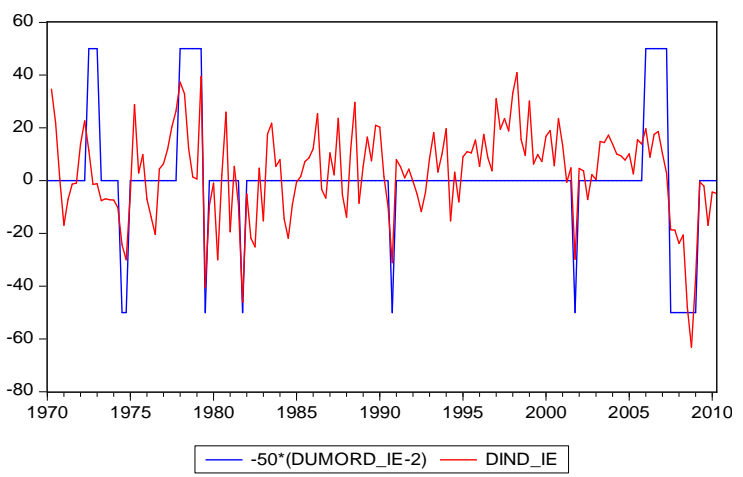


$\underline{\text { Italy }}$

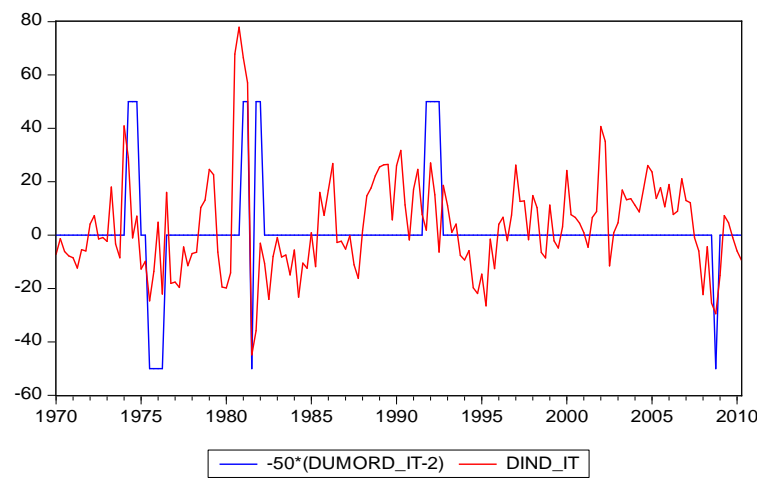

Netherlands

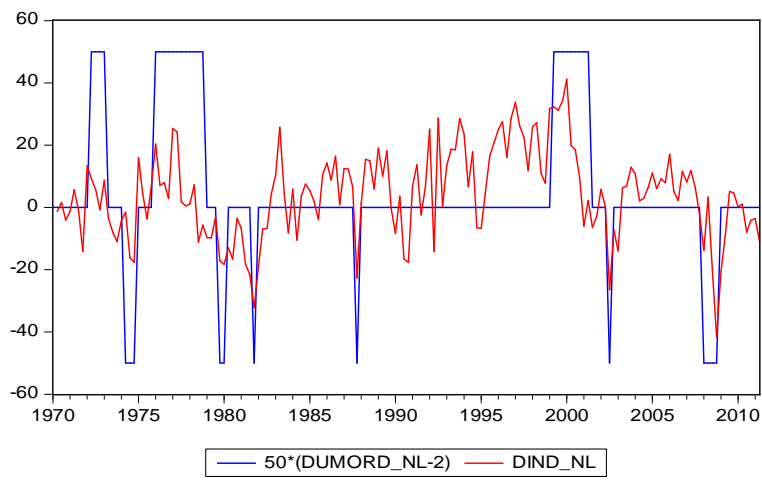

$\underline{\text { New Zealand }}$

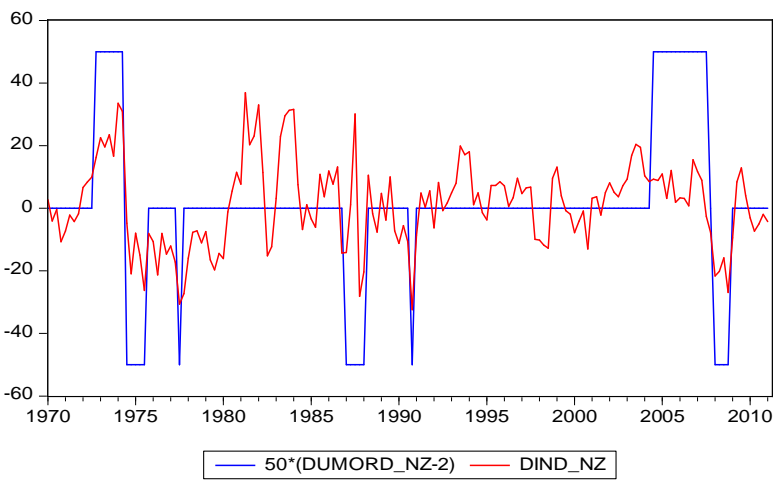

\section{$\underline{\text { Sweden }}$}

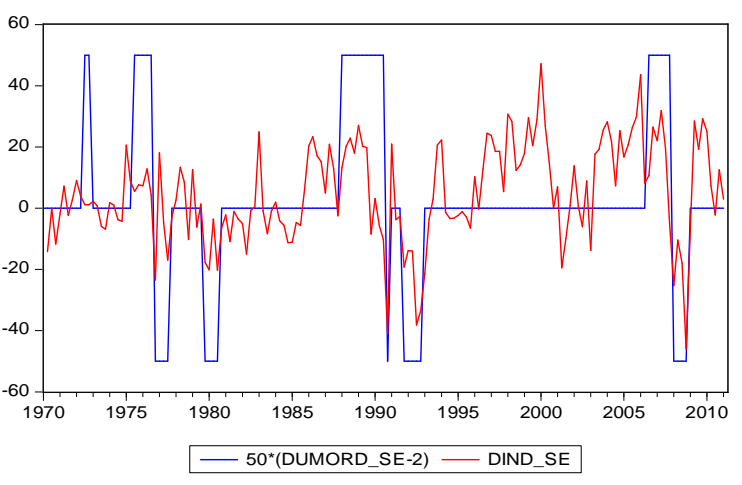

\section{$\underline{\text { Japan }}$}

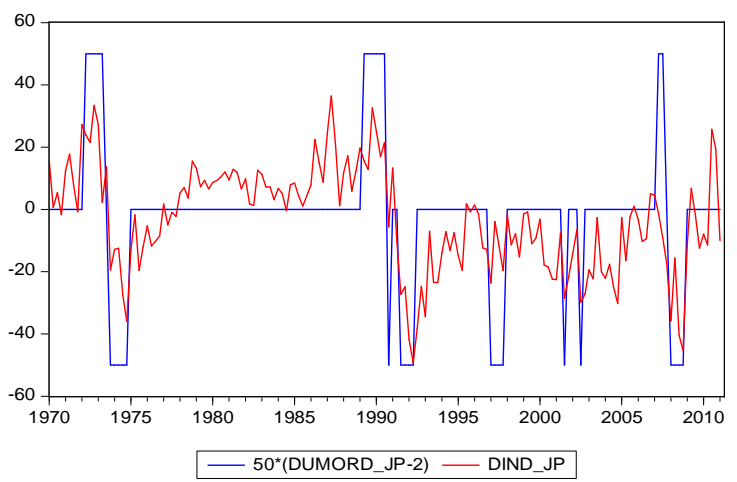

Norway

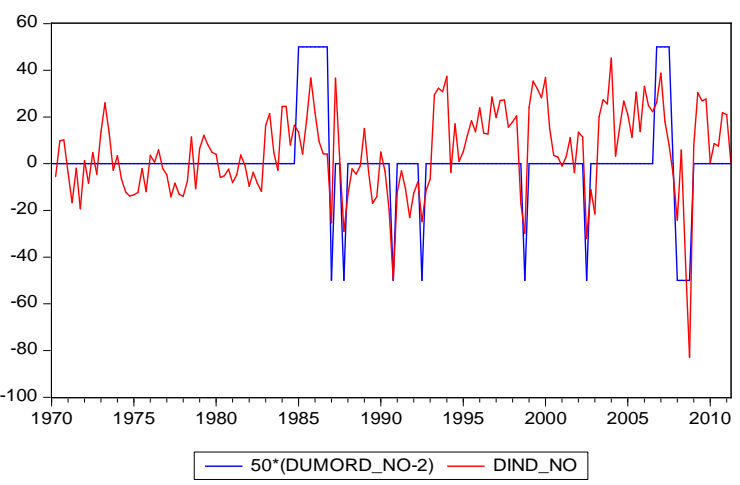

Portugal

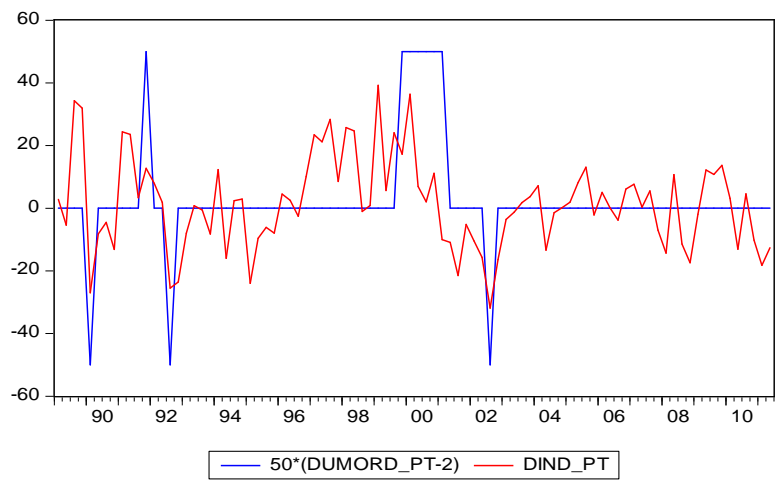

$\underline{\text { Euro area }}$

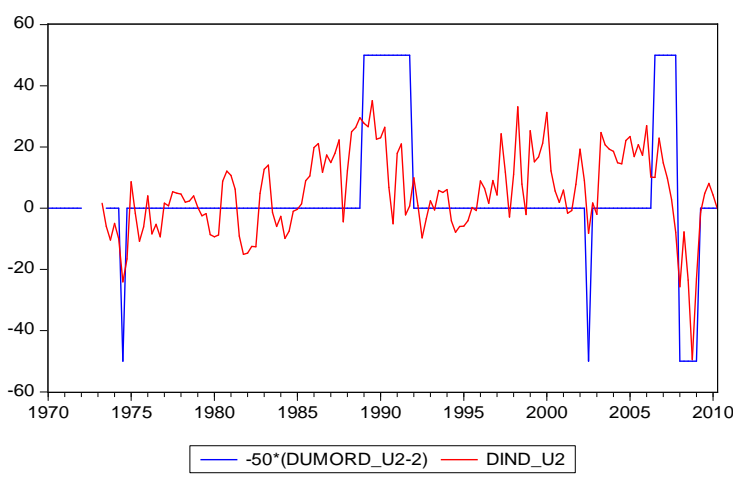


United Kingdom

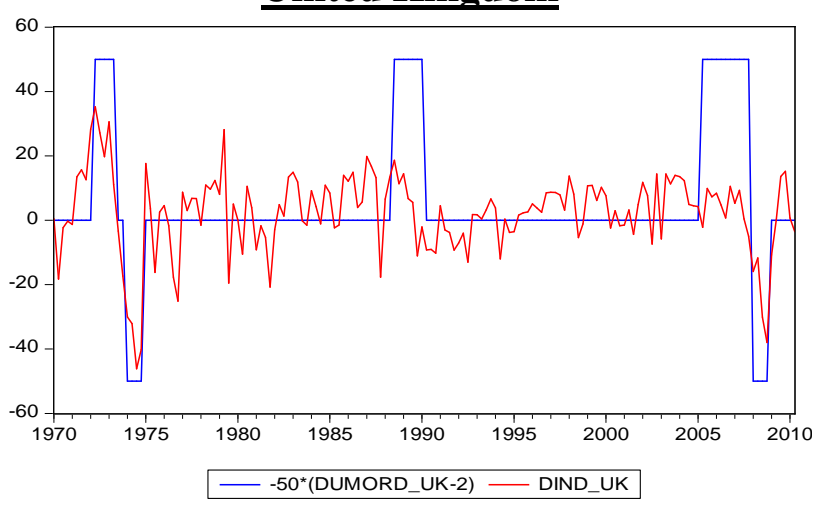

$\underline{\text { United States }}$

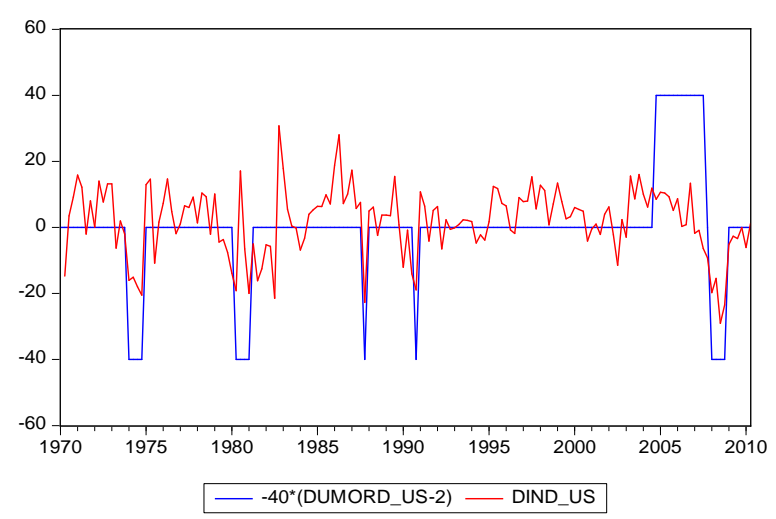

Figure 1. Developments in the changes of the composite indicators and boom-normal-bust-periods in the main OECD countries and the euro area

Note about the above figure:

Note 1. The solid red line represents the changes of the composite indicator of each respective country, while the blue line represents the boom-normal-bust-periods. It is redefined in the sense that the normal period is equal to zero, the boom phase are positive and the bust periods are negative.

The summarized exhibitions are given in Figure 2. Panel A gives the number of boom periods. The following observations seem worth noting. First, booms seem to be concentrated around three main periods. The first period is in the 1970s before the first oil price shock, the second period includes the end of the 1980s and the beginning of the 1990s, following the oil price trough in 1986, while the last cluster is around 2006-2007. Taken together, these observations lead to the conclusion that an analysis taking into account heterogeneities across countries and time has to be adopted. Panel B gives the number of bust periods. The busts seem to be less concentrated than booms and the number of busts periods (230) is lower than the number of booms (293). Moreover, they are shorter. There are two clusters. One exists after the first oil price shock. The second is around 2008-2009. Moreover, lot of busts of the second cluster directly succeeds a boom. (see also Figure 1). 
Panel A:

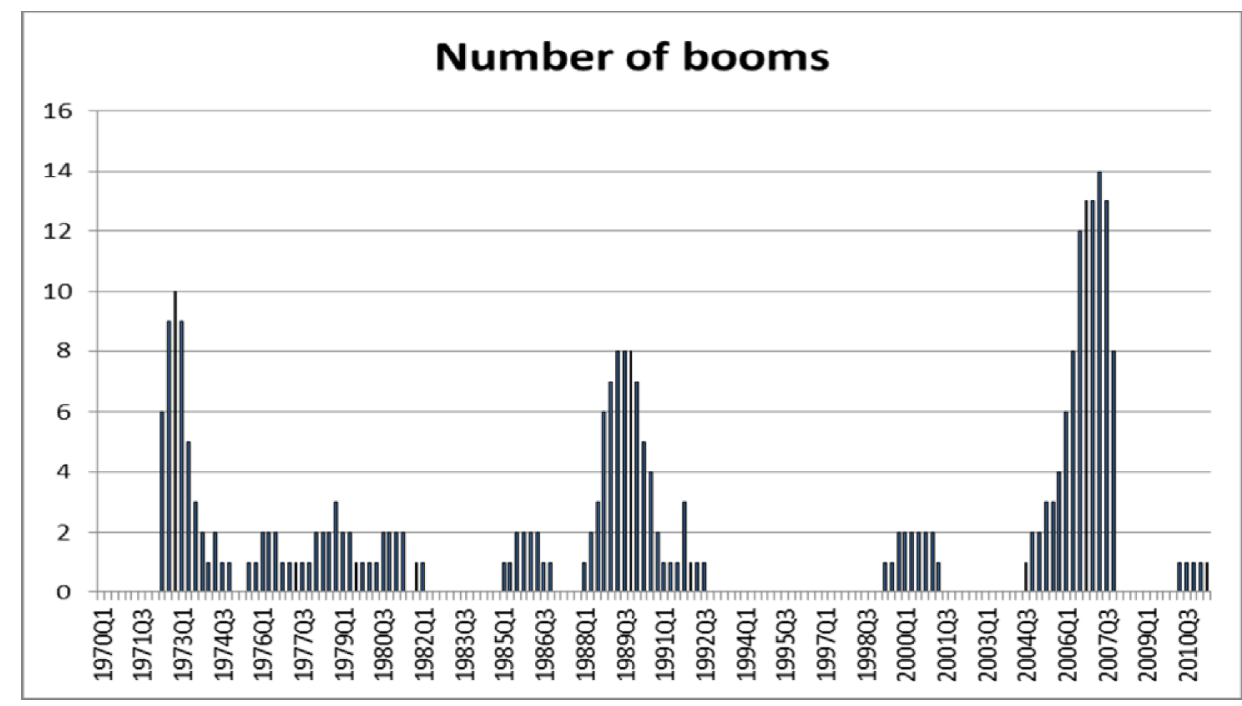

Panel B:

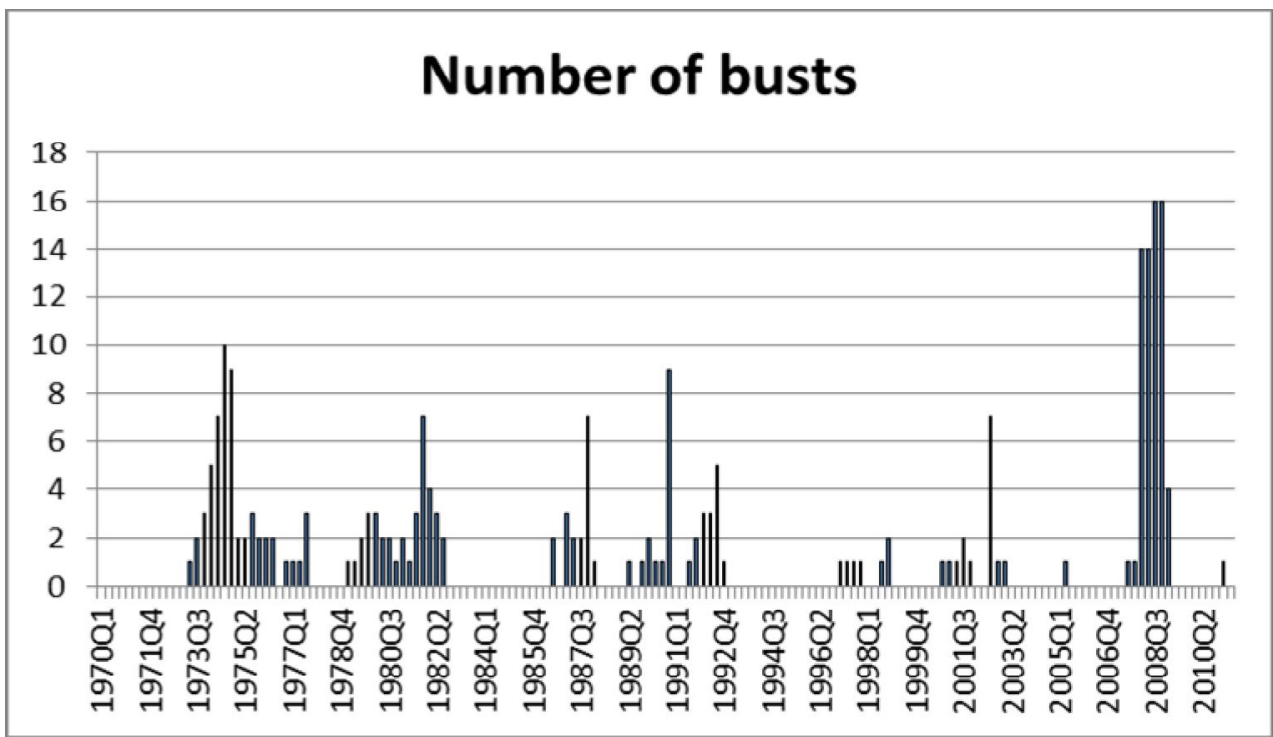

Figure 2. Panel A gives the number of booms in each period; Panel B gives the number of busts in each period.

\subsection{Empirical Results}

After having selected the boom and bust periods the three different phases demand the use of ordered probit or logit model (see Singh 2009). Since the logit approach has advantages to detect extreme cases we use ordered logit models which are a limited dependent variable model to predict these different phases of financial development. The explanatory variables are not transformed into dummy variables but are included in a linear fashion. The probability that extreme situations (booms or busts) occur is assumed to be a function of a vector of explanatory variables. The model is based on the latent regression function 


$$
y_{t}^{*}=x_{t}^{\prime} \beta+\varepsilon
$$

The observed y is determined by using $y_{t}^{*}$ which is provided as follows

$$
y_{t}=\left\{\begin{array}{lll}
1 & \text { if } & y_{t}^{*} \leq \gamma_{1} \\
2 & \text { if } & \gamma_{1} \leq y_{t}^{*} \leq \gamma_{2} \\
3 & \text { if } & y_{t}^{*}>\gamma_{2}
\end{array}\right.
$$

In the latent regression function $\varepsilon$ follows a logistic distribution and $y^{*}$ is unobserved, but what is observed is their classified category $y_{t}$ in (5). The ordered logit equation gives the probabilities of classifying different categories given as

$$
\begin{gathered}
\operatorname{Pr}\left(y_{t}=1 \mid x_{t}, \beta\right)=F\left(\gamma_{1}-x_{t}^{\prime} \beta\right) \\
\operatorname{Pr}\left(y_{t}=2 \mid x_{t}, \beta\right)=F\left(\gamma_{2}-x_{t}^{\prime} \beta\right)-F\left(\gamma_{1}-x_{t}^{\prime} \beta\right) \\
\operatorname{Pr}\left(y_{t}=3 \mid x_{t}, \beta\right)=1-F\left(\gamma_{2}-x_{t}^{\prime} \beta\right)
\end{gathered}
$$

Where $y_{t}$ is the financial development dummy series and $x_{t}$ a set of explanatory variables, $\beta$ is a vector of free parameters to be estimated and $F$ is the logistic distribution function which ensures that the predicted outcome of the model always lies between 0 and 1 . The direction of the effect of a change in $x_{t}$ depends on the sign of the $\beta$ coefficient. The coefficients estimated by these models cannot be interpreted as the marginal effect of the independent variable on the dependent variable as $\beta$ is weighted by the factor $f$ the logistic density function that depends on all regressors. Nevertheless for the extreme situations the effect of explanatory variables on the probability of getting the specified state by considering the marginal effect which is defined as

$$
\begin{array}{r}
\partial \operatorname{Pr}\left(y_{t}=1 \mid x_{t}, \beta\right) / \partial x_{t}=-\beta f\left(\gamma_{1}-x_{t}^{\prime} \beta\right) \\
\partial \operatorname{Pr}\left(y_{t}=2 \mid x_{t}, \beta\right) / \partial x_{t}=-\beta\left[f\left(\gamma_{2}-x_{t}^{\prime} \beta\right)-f\left(\gamma_{1}-x_{t}^{\prime} \beta\right)\right] \\
\partial \operatorname{Pr}\left(y_{t}=3 \mid x_{t}, \beta\right) / \partial x_{t}=\beta f\left(\gamma_{2}-x_{t}^{\prime} \beta\right)
\end{array}
$$


Thus the sign of $\beta$ shows the direction of the change in the probability of falling in the bust phase, when $x_{t}$ changes. $\operatorname{Pr}\left(y_{t}=1\right)$ changes in the opposite direction of the sign of $\beta$, while $\operatorname{Pr}\left(y_{t}=3\right)$ (boom phase) changes in the same direction as that of the sign of $\beta$. Hence a positive coefficient in the model may be interpreted that the corresponding variable has potential in raising the predictive probability of booms.

The empirical analysis in this paper will be based on the second approach and make use of pooled ordered logit techniques. As already mentioned, the fundamental variables are grouped into monetary, real and financial variables categories, and specified in form of either annual or quarterly growth rates and/or as deviations from a trend and/or as ratios to GDP. ${ }^{9}$

Applying logit techniques for our unbalanced data set enables us to estimate the probability of occurrence of a composite indicator development in the next quarter. In order to compare the performance across the several ordered logit models, we are looking at the significance of the coefficients and the pseudo $\mathrm{R}^{2}$. As for the next step regarding the ordered logit estimations, we start off from the models selected in Gerdesmeier, Reimers and Roffia $(2010,2011)$ and test different lags for all the explanatory variables. In a subsequent step, we tested the inclusion of several measures of interest rates (spread, short and long-term interest rates) and finally we tested the significant of other variables, such as real GDP and stock prices.

Table 1. Results of the preferred specification

\begin{tabular}{|l|r|c|c|}
\hline Variable & Coefficient & Standard error & Z-Statistic \\
\hline D4_ncl_gap_1 & 0.404 & $(0.074)$ & 5.447 \\
\hline D4_ncl_gap_2 & -0.320 & $(0.072)$ & 4.396 \\
\hline D4_nhp_gap_1 & 0.087 & $(0.014)$ & 6.077 \\
\hline D1_nhp_1 & 0.200 & $(0.029)$ & 7.000 \\
\hline D1_nhp_4 & -0.059 & $(0.030)$ & 1.985 \\
\hline D4_n_sto_1 & 0.034 & $(0.004)$ & 7.744 \\
\hline D4_n_sto_2 & -0.019 & $(0.004)$ & 4.482 \\
\hline Spread_1 & 0.084 & $(0.025)$ & 3.298 \\
\hline D1_hicp_1 & -0.340 & $(0.051)$ & 6.627 \\
\hline Limit_2 & -2.986 & & \\
\hline Limit_3 & 2.646 & & \\
\hline Pseudo R & 0.162 & & \\
\hline
\end{tabular}

Notes: D4_ncl_gap_1: y-o-y change of the gap of nominal lending to the trend nominal lending using the Christiano-Fitzgerald filter lagged by one quarter, D4_ncl_gap_2: y-o-y change of the gap of nominal lending to the trend nominal lending using the Christiano-Fitzgerald filter lagged by two quarters, D4_nhp_gap_1: y-o-y change of the gap of nominal house prices to the trend nominal house prices using the Christiano-Fitzgerald filter lagged by one quarter, D1_nhp_1: q-o-q change of the house prices lagged by one quarter, D1_nhp_4: q-o-q change of the house prices lagged by four quarters, D4_n_sto_1: y-o-y change of the nominal stock

To calculate the trend, we make use of the Christiano-Fitzgerald filter (2003), since the Hodrick-Prescott filter is known to suffer from an end-of-sample problem. 
prices lagged by one quarter, D4_n_sto_2: y-o-y change of the nominal stock prices lagged by two quarters, Spread_1: long-term rate minus short term rate lagged by one quarter, D1_hicp_1: q-o-q change of the consumer price index lagged by 1 quarter.

Table 1 presents the results of the preferred specification which includes credit growth gap, house price growth gap, house price changes, inflation rate, the interest rates spread and the stock price growth. ${ }^{10}$ Concentrating on the boom phases to explain the sign of the coefficients the estimate confirm that an increase of the lending-gap positively influence the occurrence of a boom period. This is in line with results of Borio et al. (1994) and Gerdesmeier et al. (2011). Moreover, raises in house price gaps, in house prices and stock prices positively affect the probability of booms. To some extent it presents persistence in the markets and confirms results of Candelon et al. (2011). The positive coefficient of the spread variable may be explained by link of the financial market to the real economy. A positive difference between the short term rate and the long term rate shows the expansive stance of monetary policy (see Estrella \& Hardouvelis, 1991). This affects the aggregate demand of the economy. Economic agents may increase the investment in the house markets and the increase in aggregate demand expands the profits of companies, which both influence our financial indicator. The coefficient of the inflation rate is negative and do not fuel the boom periods. It is worth noting that the growth rate of GDP or the investment-output-ratio have no significant coefficient. These variables are deleted. This notwithstanding, the coefficient values are not as intuitive to interpret. In fact, eq.(9) shows that the coefficients are not constant marginal effects of the variable on boom probability since the variable's effect is conditional on the values of all other explanatory variables. Rather, the slope-coefficients represent the effects of $X_{t}$ the respective right-hand variables when all other variables are held at their sample means. The pseudo $\mathrm{R}^{2}$ is 0.16 .

As regards the threshold value of the probability, designing a good forecasting model requires balancing the number of false alarms and the number of failures. In general, the value depends on the costs related to the two different types of errors and their assessment by the policy maker. In this section, we use the maximum of predicted probability to determine the existence of a category. Using this decision rule the number of correct calls is $3.9 \%$ of busts, $98.7 \%$ of normal and $14.3 \%$ of booms, respectively. It is apparent that this decision rule prefers the normal situation. It will be helpful if the decision maker gives all situations the same weight. In section 4.3 the issue will be discussed more deeply.

\section{Assessing the Robustness of the Model}

\subsection{Stability of the Coefficient Estimates}

In order to check the stability of our results, we conduct two procedures. Firstly, we examine the time invariance. Secondly, the coefficient stability in respect of the pooled countries is investigated. Turning to the first approach, we start with a sample end in 2000Q4. In the next

10 The inclusion of the spread as indicator for asset price booms may reflect the fact that in the literature it has been shown that the term spread is a good measure to predict future output growth. See, for instance, Estrella and Hardouvelis (1991). 
step the sample size is extended by four quarters. The last sample ended in 2011Q2. The results of this comparison are reported in Table 2. In all samples the signs of the coefficients are time invariant. Moreover, the coefficients are relatively stable. In line with an extended sample size, the standard errors of the coefficients are declining (given in parentheses).

The second approach analyses the stability of the coefficient regarding the used cross section members. Therefore, the pool varies in such a way that each country is excluded of the pool. The remaining countries establish the pool. In Table 3 the results are given. Each column has given a headline. This indicates which country is excluded. The following cell includes the estimate of a coefficient. It is apparent that the estimates are very stable. The exclusion of a country does not change the sign of any coefficient. Moreover, the magnitude of the coefficients is more or less the same.

Table 2. Coefficient estimates of different sample ends.

\begin{tabular}{|c|c|c|c|c|c|c|c|c|c|c|c|c|}
\hline \multirow[b]{2}{*}{ Variable } & \multicolumn{12}{|c|}{ End of sample } \\
\hline & $2000 q 4$ & $2001 q 4$ & $2002 q 4$ & $2003 q 4$ & $2004 q 4$ & $2005 q 4$ & $2006 q 4$ & $2007 q 4$ & $2008 \mathrm{q} 4$ & $2009 q 4$ & $2010 q 4$ & $2011 q 2$ \\
\hline \multirow[t]{2}{*}{ D4_ncl_gap_1 } & .352 & .339 & .355 & .362 & .356 & .334 & .383 & .328 & .427 & .418 & .410 & .404 \\
\hline & $(.091)$ & $(.088)$ & $(.087)$ & $(.087)$ & $(.087)$ & $(.084)$ & $(.082)$ & (.079) & $(.075)$ & $(.075)$ & $(.074)$ & $(.074)$ \\
\hline \multirow[t]{2}{*}{ D4_ncl_gap_2 } & -.293 & -.277 & -.292 & -.298 & -.286 & -.266 & -.288 & -.193 & -.345 & -.331 & -.325 & -.320 \\
\hline & $(.089)$ & $(.087)$ & $(.086)$ & $(.086)$ & $(.086)$ & $(.083)$ & $(.081)$ & $(.078)$ & $(.074)$ & $(.074)$ & $(.073)$ & $(.073)$ \\
\hline \multirow[t]{2}{*}{ D4_nhp_gap_1 } & .108 & .106 & .103 & .103 & .102 & .108 & .104 & .077 & .086 & .085 & .087 & .087 \\
\hline & (.017) & $(.016)$ & $(.016)$ & $(.016)$ & (.016) & $(.016)$ & (.016) & $(.015)$ & (.014) & $(.014)$ & $(.014)$ & (.014) \\
\hline \multirow[t]{2}{*}{ D1_nhp_1 } & .189 & .193 & .190 & .190 & .189 & .180 & .168 & .181 & .210 & .203 & .202 & .200 \\
\hline & $(.033)$ & $(.033)$ & $(.033)$ & $(033)$ & $(.033)$ & $(.032)$ & $(.032)$ & $(.031)$ & (.029) & (.029) & $(.029)$ & (.029) \\
\hline \multirow[t]{2}{*}{ D1_nhp_4 } & -.100 & -.094 & -.090 & -.095 & -.092 & -.093 & -.085 & -.063 & -.057 & -.062 & -.060 & $-.059)$ \\
\hline & $(.035)$ & $(.034)$ & $(.034)$ & $(.034)$ & $(.034)$ & $(.034)$ & $(.033)$ & $(.032)$ & $(.030)$ & $(.030)$ & $(.030)$ & $(.029)$ \\
\hline \multirow[t]{2}{*}{ D4_n_sto_1 } & .032 & .032 & .032 & .031 & .031 & .030 & .028 & .028 & .037 & .035 & .034 & .034 \\
\hline & $(.006)$ & $(.005)$ & $(.005)$ & $(.005)$ & $(.005)$ & $(.005)$ & $(.005)$ & $(.005)$ & $(.005)$ & $(.005)$ & $(.004)$ & $(.004)$ \\
\hline \multirow[t]{2}{*}{ D4_n_sto_2 } & -.020 & -.019 & -.018 & -.016 & -.016 & -.016 & -.013 & -.014 & -.020 & -.021 & -.019 & -.019 \\
\hline & $(.005)$ & $(.033)$ & $(.005)$ & $(.005)$ & $(.005)$ & $(.005)$ & $(.005)$ & $(.005)$ & $(.005)$ & $(.004)$ & $(.004)$ & $(.004)$ \\
\hline \multirow[t]{2}{*}{ Spread_1 } & .116 & .119 & .112 & .114 & .112 & .106 & .089 & .064 & .068 & .077 & .082 & .084 \\
\hline & $(.028)$ & $(.028)$ & $(.028)$ & $(.028)$ & $(.028)$ & $(.028)$ & $(.028)$ & $(.027)$ & $(.026)$ & $(.026)$ & $(.026)$ & $(.025)$ \\
\hline \multirow[t]{2}{*}{ D1_hicp_1 } & -.292 & -.287 & -.261 & -.256 & -.252 & -.245 & -.279 & -.361 & -.301 & -.327 & -.339 & -.340 \\
\hline & $(.061)$ & $(.060)$ & $(.059)$ & $(.058)$ & $(.059)$ & $(.058)$ & $(.057)$ & $(.055)$ & $(.052)$ & $(.051)$ & $(.051)$ & $(.051)$ \\
\hline Limit_2 & -3.191 & -3.155 & -3.070 & -3.099 & -3.101 & -3.109 & -3.212 & -3.285 & -2.825 & -2.938 & -2.981 & -2.986 \\
\hline Limit_3 & 2.760 & 2.793 & 2.876 & 2.918 & 2.969 & 2.952 & 2.772 & 2.537 & 2.721 & 2.645 & 2.652 & 2.646 \\
\hline Pseudo $\mathrm{R}^{2}$ & .158 & .155 & .152 & .152 & .151 & .150 & .160 & .162 & .165 & .164 & .163 & .162 \\
\hline
\end{tabular}

Notes: See table 1. 
Table 3. Coefficient estimates of reduced cross section dimension

\begin{tabular}{|c|c|c|c|c|c|c|c|c|c|c|c|c|c|c|c|c|c|c|}
\hline \multirow[t]{2}{*}{ Variable } & \multicolumn{18}{|c|}{ Pooled estimates without specified country } \\
\hline & $-\mathrm{U} 2$ & -au & -de & -jp & -uk & us & $-\mathrm{ca}$ & $-\mathrm{ch}$ & $-\mathrm{dk}$ & -es & $-f r$ & -ie & -it & $-n l$ & -se & -no & $-n z$ & $-\mathrm{pt}$ \\
\hline D4_ncl_g_1 & .400 & .391 & .409 & .407 & .402 & .351 & .390 & .410 & .420 & .437 & .417 & .421 & .398 & .405 & .491 & .376 & .341 & .433 \\
\hline D4_ncl_g_2 & -.318 & -.304 & -.326 & -.323 & -.322 & -.266 & -.303 & -.328 & -.341 & -.350 & -.326 & -.338 & -.314 & .323 & -.399 & -.288 & -.252 & -.355 \\
\hline D4_nhp_g_1 & .083 & .092 & .091 & .093 & .096 & .086 & .088 & .088 & .091 & .074 & .079 & .090 & .092 & .081 & .074 & .092 & .089 & .087 \\
\hline D1_nhp_1 & .204 & .196 & .191 & .183 & .192 & .197 & .199 & .210 & .204 & .212 & .207 & .218 & .190 & .208 & .208 & .197 & .192 & .197 \\
\hline D1_nhp_4 & -.060 & -.068 & -.071 & -.061 & -.064 & -.062 & -.054 & -.059 & -.068 & -.024 & -.049 & -.055 & -.057 & .073 & -.050 & -.059 & -.058 & -.060 \\
\hline D4_n_sto_1 & .033 & .034 & .033 & .033 & .033 & .034 & .035 & .033 & .032 & .034 & .034 & .034 & .037 & .034 & .033 & .036 & .034 & .034 \\
\hline D4_n_sto_2 & -.018 & -.019 & -.017 & -.020 & -.019 & -.019 & -.020 & -.019 & -.016 & -.020 & -.021 & -.019 & -.022 & -.019 & -.020 & -.020 & -.018 & -.019 \\
\hline Spread_1 & .088 & .084 & .085 & .084 & .095 & .093 & .074 & .075 & .096 & .082 & .090 & .076 & .088 & .063 & .074 & .099 & .086 & .080 \\
\hline D1_hicp_1 & -.335 & -.336 & -.356 & -.335 & -.335 & -.310 & -.341 & -.336 & -.317 & -.315 & -.363 & -.375 & -.360 & .349 & -.368 & -.345 & -.317 & -.330 \\
\hline Pseudo R ${ }^{2}$ & .161 & .167 & .167 & .162 & .159 & .161 & .166 & .165 & .158 & .161 & .164 & .164 & .167 & .156 & .163 & .164 & .160 & .162 \\
\hline
\end{tabular}

Notes: See table 1; U2: euro area, au: Australia, de: Germany, jp: Japan, uk: United Kingdom, us: United States, ca: Canada, ch: Switzerland, dk: Denmark, es: Spain, fr: France, ie: Ireland, it: Italy, nl: The Netherlands, se: Sweden, no: Norway, nz: New Zealand, pt: Protugal.

\subsection{Testing for the Impact of Different Forecasting Horizons}

It can be argued that a forecasting horizon of 1 quarter is too small. Therefore, the forecasting horizon should be extended up to five quarters. The results are reported in Table 4. It can be noticed that the information content of the variables are not stable. The coefficients of credit gaps increase, however its sum becomes smaller. The size of the coefficient of the house price gap is slightly higher. But the coefficient of the house price change is not stable. Increasing the forecasting horizon reduces its coefficient. It becomes insignificant. The same difficulties are apparent for the stock price changes. Their coefficients include short term affects. However, the spread coefficient is stable. As expected, the pseudo $\mathrm{R}^{2}$ declines with increasing forecasting horizon.

Table 4. Coefficients and statistics of the preferred specification for extended forecast horizons

\begin{tabular}{|c|c|c|c|c|c|}
\hline \multicolumn{7}{|l|}{ Forecasting horizon } \\
\hline Variable & 1 & 2 & 3 & 4 & 5 \\
\hline D4_ncl_gap_1 & $.404(.074)$ & $.586(.074)$ & $.722(.074)$ & $.800(.075)$ & $.770(.074)$ \\
\hline D4_ncl_gap_2 & $-.320(.073)$ & $-.521(.073)$ & $-.678(.073)$ & $-.781(.073)$ & $-.778(.073)$ \\
\hline D4_nhp_gap_1 & $.087(.014)$ & $.091(.014)$ & $.106(.014)$ & $.121(.014)$ & $.094(.014)$ \\
\hline D1_nhp_1 & $.200(.029)$ & $.153(.028)$ & $.084(.028)$ & $-.031(.029)$ & $-.019(.033)$ \\
\hline D1_nhp_4 & $-.059(.029)$ & $-.072(.029)$ & $-.118(.029)$ & $-.128(.029)$ & $-.079(.029)$ \\
\hline D4_n_sto_1 & $.034(.004)$ & $.024(.004)$ & $.017(.004)$ & $.006(.004)$ & $-.005(.004)$ \\
\hline D4_n_sto_2 & $-.019(.004)$ & $-.019(.004)$ & $-.018(.004)$ & $-.012(.004)$ & $-.003(.004)$ \\
\hline Spread_1 & $.084(.025)$ & $.095(.025)$ & $.101(.025)$ & $.099(.025)$ & $.089(.025)$ \\
\hline D1_hicp_1 & $-.340(.051)$ & $-.279(.051)$ & $-.164(.051)$ & $-.038(.051)$ & $-.050(.051)$ \\
\hline Limit_2 & -2.986 & -2.981 & -3.012 & -3.021 & -2.881 \\
\hline Limit_3 & 2.646 & 2.458 & 2.281 & 2.117 & 2.110 \\
\hline Pseudo R 2 & .162 & .136 & .116 & .096 & .074 \\
\hline
\end{tabular}

Notes: See table 1 


\subsection{Determining the Threshold}

In the previous analyses we used as decision rule the maximum of predicted probability to determine the category. This assumes an equal weight of the decision maker for all categories. Having in mind the high costs of financial crisis manifested in form of large output losses, rising unemployment and huge public deficits (see for example Bussiere and Fratzscher 2006 or Detken and Smets 2004) it is reasonable to assume that decision makers give the crisis a higher weight. Assuming that they are concentrated on crisis they may have a lost function $L(T)$ of the form:

$$
L(T)=\theta \quad \operatorname{Pr}^{N S}(T)+(1-\theta) \operatorname{Pr}^{S}(T)
$$

with $\operatorname{Pr}^{N S}(T)$ as the probability of a missing a crisis and $\operatorname{Pr}^{S}(T)$ as the probability of issuing the signal that a crisis will occur. $\theta$ can be interpreted as the relative cost of missing a crisis or the decision maker's degree of relative risk-aversion of missing a crisis. The results of losses do not only depend on the risk aversion but also on the threshold T. To show the implications of different thresholds the decision rule is changed. The signal is given regarding the maximum of the predicted probability of booms and busts. If the maximum of these two categories is greater than the threshold a signal for this category is given. If the maximum is lower a signal of a normal period is taken. The results for different $\mathrm{T}$ are given in the Table 5. It is apparent that an increase of the threshold value raises the number of correct signals over all categories. However, concentration on crisis a lower threshold is sensible. In contrast an equal weight of all three phases would imply a high threshold. The number of correct signals is at maximum for $\mathrm{T}=.50$. This measure has the drawback that it is dominated by the good results for the normal phase. This is avoided by using a modification relying on the definition of conditional forecast (see Mizen and Tsoukas, 2011). It is:

$$
C P_{i}=\frac{\frac{1}{J} \sum_{j=1}^{J} 1\left(\hat{q}_{j}=i\right)\left(q_{j}=i\right)}{\frac{1}{J} \sum_{j=1}^{J} 1\left(q_{j}=i\right)}
$$

where $\mathrm{I}$ is the number of categories and $\mathrm{J}$ is the number of observations. The $C P_{i}$ 's are calculated as the proportion of correct predictions divided by the total of each row. The modified measure is

$$
C P=\frac{1}{I-1}\left(\sum_{i=0}^{I-1} C P_{i}-1\right)
$$

where $-\frac{1}{I-1} \leq C P \leq 1$ is. In the contingency table $C P$ is the unweighted average of $C P_{i}$ 's minus one to correct for the stopped clock phenomenon. This modifies the measure of predictive ability to discount the influence of the dominant outcome. Only when the predictor 
is accurate for all categories it will obtain a high $\mathrm{CP}$ value. The empirical values are given in last row of Table 5. The best value is obtained for the threshold of .10. The main conclusion that can be drawn from this line compared to the line above is that the outcome is highly dominated by the normal phase.

Table 5. Results of signals for different thresholds

\begin{tabular}{|c|c|c|c|c|c|c|c|c|c|c|c|c|}
\hline Category & Signal & \multicolumn{10}{|c|}{ Threshold } \\
\cline { 3 - 14 } & & .50 & .45 & .40 & .35 & .30 & .25 & .20 & .15 & .11 & .10 & .09 \\
\hline \multirow{2}{*}{ Boom } & Correct & 36 & 40 & 46 & 55 & 79 & 98 & 130 & 169 & 207 & 217 & 224 \\
\cline { 2 - 14 } & False & 14 & 23 & 35 & 62 & 95 & 146 & 234 & 371 & 624 & 706 & 812 \\
\hline \multirow{2}{*}{ Normal } & Correct & 2152 & 2136 & 2109 & 2060 & 1996 & 1909 & 1768 & 1524 & 1102 & 971 & 800 \\
\cline { 2 - 15 } & False & 441 & 432 & 418 & 403 & 368 & 344 & 284 & 222 & 133 & 106 & 84 \\
\hline \multirow{2}{*}{ Bust } & Correct & 9 & 14 & 21 & 27 & 37 & 41 & 66 & 85 & 126 & 139 & 150 \\
\cline { 2 - 13 } & False & 18 & 25 & 41 & 63 & 95 & 132 & 188 & 299 & 478 & 531 & 600 \\
\hline \multirow{2}{*}{ Sum } & Correct & 2197 & 2190 & 2176 & 2142 & 2112 & 2048 & 1964 & 1778 & 1435 & 1327 & 1174 \\
\hline CP & & .082 & .097 & .118 & .137 & .191 & .216 & .300 & .361 & .427 & .445 & .443 \\
\hline
\end{tabular}

\section{Conclusions}

For central banks it is important to use early warning indicators to assess the possible implications of large asset price movements and the building up of financial imbalances in the economy. In this respect, several studies have shown that the analysis of credit developments may be very useful in this respect. This paper contributes to this literature by splitting up the development of a financial indicator into bust, normal and boom phases to describe the whole boom-bust-cycle. For these cycles it is investigated whether credit indicators can play an important role in detecting the stylized development of asset prices by looking at the evidence stemming from a sample of 17 OECD industrialised countries and the euro area over the period 1969 Q1 - 2011 Q2.

By using an asset price composite indicator (which incorporates developments in both the stock price and house price markets) and following the methodology illustrated in Gerdesmeier, Reimers and Roffia (2010, 2011), an empirical analysis is carried out based on a pooled ordered logit-type approach, which considers several economic variables. According to statistical tests, credit aggregates (growth gap), and house price changes (and growth gap) jointly with developments in stock prices and the interest rate spread turn out to be the best indicators which help to forecast composite indicator development. These results demand, for example, central banks to observe the development of credit aggregates as well as stock and house markets to get signals of mispricings at these markets. Moreover, the term spread shows a channel to affect the probability of boom and bust phases. Hence, it indicates that an monetary authority can lend against the wind to avoid devastating effects on the real economy caused by boom-busts-cycles.

The model is cross-checked vis-à-vis the estimation methods, forecasting horizon and probability thresholds and it turns out to be quite robust. These results reflect the good performance to estimate the normal situation. To capture the extreme cases, which are turning 
points of the development, is much more difficult. These phases are relatively short and show a low persistence. To be more successful for the boom and bust phases an extension of the data base could be promising. In this sense for further research higher frequency or mixed frequency approaches might be fruitful venues.

Acknowledgement: The author would like to thank Andrew Berg (IMF) for this help to conduct the logit estimation using EViews as well as Yoana Bogdanova and Christian Reinick for their research assistance. Moreover, the author thanks an anonymous referee for the helpful comments. The author receives financial support for this research project of the Hochschule Wismar.

\section{References}

Adalid, R., \& Detken, C. (2007). Liquidity shocks and asset price boom/bust cycles. ECB Working Paper, No. 732.

Alessi, L., \& Detken, C. (2009). 'Real time' early warning indicators for costly asset price boom/bust cycles: a role for global liquidity, ECB Working Paper, No. 1039.

Andreou, I., Dufrénot, G., Sand-Zantman, A., \& Zdzienicka-Durand, A. (2007). A forewarning indicator system for financial crises: the case of six central and eastern European countries. William Davidson Institute Working Paper, University of Michigan, No. 901.

Angello, L., \& Schuknecht. (2011). Booms and busts in housing markets: Determinant and implications. Journal of Housing Economics, 20(3). 171-190. http://dx.doi.org/10.1016/j.jhe.2011.04.001

Babecký, J., Havránek, T., Mateju, J., Rusnák, M., Smidková, K., \& Vasicek, B. (2011). Early Warning Indicators of Crises Incidence: Evidence from a panel of 40 developed countries, IES Working Paper 36/2011.

Berg, A., \& Pattillo, C. (1999). Predicting currency crises: the indicators approach and an alternative. Journal of International Money and Finance, 18(4). 561-586. http://dx.doi.org/10.1016/S0261-5606(99)00024-8

Borio, C., \& Lowe, P. (2002). Asset prices, financial and monetary stability: exploring the nexus, BIS Working Papers, No 114.

Borio, C., \& Drehmann, M. (2009). Assessing the risk of banking crises-revisited. BIS Quarterly Review, March.

Borio, C., Kennedy, N., \& Prowse, S. D. (1994). Exploring aggregate asset price fluctuations across counties, measurement, determinants, and monetary policy implications. BIS Economic Papers, No. 40.

Brunnermeier, M. K. (2008). Bubbles. In Durlauf, S.N., \& Bluem, L.E. (Eds.), New Palgrave Dictionary of Economics, $2^{\text {nd }} \quad$ ed., $\quad$ Macmillan: London. http://dx.doi.org/10.1057/9780230226203.0168

Bussiere, M., \& M. Fratzscher. (2006). Towards a new early warning system of financial crisis. 
Journal of International Money and Finance, 25. 953-973. http://dx.doi.org/10.1016/j.jimonfin.2006.07.007

Candelon, B., Dumitrescu, E.-I., Hurlin, C., \& Palm, F. C. (2011) Modeling Financial Crises Mutation, Discussion paper Maastricht University.

Christiano, L., \& Fitzgerald, T. J. (2003). The Band Pass filter. International Economic Review. 44(2), 435-465. http://dx.doi.org/10.1111/1468-2354.t01-1-00076

Detken, C., Gerdesmeier, D., \& Roffia, B. (2010). Interlinkages between money, credit and asset prices and their implications for consumer price inflation: recent empirical work. In: Papademos, L.D., \& Stark, J., (Eds.) Enhancing Monetary Analysis, European Central Bank, Frankfurt am Main, Chapter 6, 307-354,.

Detken, C., \& Smets, F. (2004). Asset price booms and monetary policy. ECB Working Paper, No. 364.

Dreger, C., \& Kholodilin, K. (2012). An early warning system to predict the house price bubbles, DIW Berlin, Discussion Paper, 1142.

ECB. (2002) The stock market and monetary policy. ECB Monthly Bulletin, February 2002.

Estrella, A., \& Hardouvelis, G. (1991). The term structure as a predictor of real economic activity. Journal of Finance, $46(2), \quad 555 \quad-\quad 576$. http://dx.doi.org/10.1111/j.1540-6261.1991.tb02674.x

Fisher, I. (1932). Booms and depressions. New York, Adelphi.

Gerdesmeier, D., Reimers, H.-E., \& Roffia, B. (2009). Asset prices misalignments and the role of money and credit money and credit. ECB Working Paper, 1068.

Gerdesmeier, D., Reimers, H.-E., \& Roffia, B. (2010). Asset prices misalignments and the role of money and credit. International Finance. 13(3), 377-407. http://dx.doi.org/10.1111/j.1468-2362.2010.01272.x

Gerdesmeier, D., Reimers, H.-E., \& Roffia, B. (2011). Early warning indicators for asset price booms. Review of Economics and Finance. 3, 1-20.

Grantham, J. (2008). Reaping the whirlwind. Quarterly Letter part 1, October, GMO Boston.

Greenspan, A. (2009). We need a better cushion against risk. Financial Times, March 27.

Helbling, T., \& Terrones, M. E. (2003). Real and financial effects of bursting asset price bubbles, IMF World Economic Outlook.

Herwartz, H., \& K. Kholodilin. (2011). In-sample and out-of-sample prediction of stock market bubbles: Cross-sectional evidence. Discussion paper DIW, 1173.

Washington, D. C. (2008). International Monetary Fund. Global financial stability, financial stress and deleveraging.

International Monetary Fund. (2010). The IMF-FSB early warning exercise, Washington 
www.imf.org/external/np/pp/eng/2010/090110.pdf

Kindleberger, C. (1978). Manias, panics and crashes: a history of financial crises. John Wiley, New York.

Mizen, P., \& Tsoukas, S. (2011) Forecasting US bond default ratings allowing for previous and initial state dependence in an ordered model. University Glasgow, Department of Economics. www.gla.ac.uk/media/media_208371_en.pdf

Prechter, R. R. Jr. (1999). The wave principle of human social behavior and the new science of socionomics, New Classics Library, Gainsville.

Singh, T. R. (2010). Ordered probit model of early warning system for predicting financial crisis in India, Discussion paper Reserve Bank of India. Mumbai.

Vogel, H. L. (2010). Financial Market Bubbles and Crashes. Cambridge University Press, Cambridge.

Yucel, Eray. (2011) A Review and Bibliography of Early Warning Models, Central Bank of the Republic of Turkey. MPRA Paper No. 32893.

Zhang, Zhiwei. (2001). Speculative attacks in the Asian crisi. IMF Working Paper. WP/01/189.

\section{Copyright Disclaimer}

Copyright reserved by the author(s).

This article is an open-access article distributed under the terms and conditions of the Creative Commons Attribution license (http://creativecommons.org/licenses/by/3.0/). 